\title{
Opportunities and Conditions for Implementation of the Social Entrepreneurship Project in the Republic of Tatarstan: Experts' Assessment
}

\author{
Alina, Mahiyanova \\ Management department at Kazan State Power Engineering \\ University \\ Kazan State Power Engineering University \\ Kazan, Russia \\ socavm@rambler.ru
}

Ruzanna Valeeva

Department of foreign languages at Kazan National Research Technical University named after A.N. Tupolev KAI

Kazan National Research Technical University named after A.N. Tupolev - KAI

Kazan, Russia nana933@list.ru

\author{
Elmira Khuzieva \\ Management department at Kazan State Power Engineering \\ University \\ Kazan State Power Engineering University \\ Kazan, Russia \\ huzievaef@mail.ru
}

\section{Tamara Filimonova}

Cyber engineering department at Kazan State Power

Engineering University

Kazan State Power Engineering University

Kazan, Russia

filimonova.tamara@bk.ru

\begin{abstract}
The article presents the theoretical and applied aspects of the analysis of possibilities and conditions for the implementation of the project of social entrepreneurship in the territory of a separate region of the Russian Federation. In the theoretical aspect, the essence of the term "social

training in courtyards, the manufacture of sports grounds; the creation of a farm on the basis of a family orphanage or boarding house; organization of classes for clubs, societies, cultural and creative development studios for youth, parents with disabled children, the poor, etc
\end{abstract} entrepreneurship" is revealed, based on the idea that the implementation of projects on social entrepreneurship, an increase in their number as a whole, is a business solution to the social problems of society. The paper reviews the works that reveal the meaning of the term "social entrepreneurship", explores the types of government measures in this direction, and considers various implemented projects that are similar in terms of a set of tasks or activities. In the applied aspect, the results of the expert survey conducted in 2019 on the topic "Social Entrepreneurship in the Republic of Tatarstan" are presented. The representatives of small and medium-sized businesses (8 respondents) and organizers of the volunteer movement (6 respondents) and directors of charitable organizations (2 respondents) acted as the experts.

Based on the results of the study, we assessed the conditions for the development of social entrepreneurship in the Republic, and the most burning issues at present. We also reviewed the difficulties that impede the development of social entrepreneurship in the Republic.

The areas that can and should be developed on the territory of the Republic were identified: the organization of social fitness centers, visits to which will be available for low-income and socially unprotected citizens, the organization of instruction and

Keywords: social entrepreneurship, project, conditions for entrepreneurship establishment, expert survey

\section{INTRODUCTION}

Raising the issue of social entrepreneurship, it is necessary, first of all, to designate the essence of this term, which is in the fact that the main characteristics of entrepreneurial activity and its focus on solving social problems of society are closely intertwined. Entrepreneurship has always been aimed at making a profit from using property, selling goods, performing some work or providing services. It is, meanwhile, closely related to the ability to take risks and make responsible decisions.

In turn, social problems of modern society are quite multivariate, diverse and their solution helps to improve people's lives, improve the quality of life, optimize the social climate in society. Thus, the implementation of projects on social entrepreneurship, an increase in their number as a whole, can be considered as a business solution to social problems of the society. 
on a five-point scale, according to which 5 points were for the best conditions and 1 point was for the worst ones. According to the data obtained, the survey participants rather positively assessed the social conditions created for development of social entrepreneurship in the Republic (2.05 points), legal (juridic) ones took the second position and economic ones (1.98 to 1.75 points) - the third (Fig. 1).

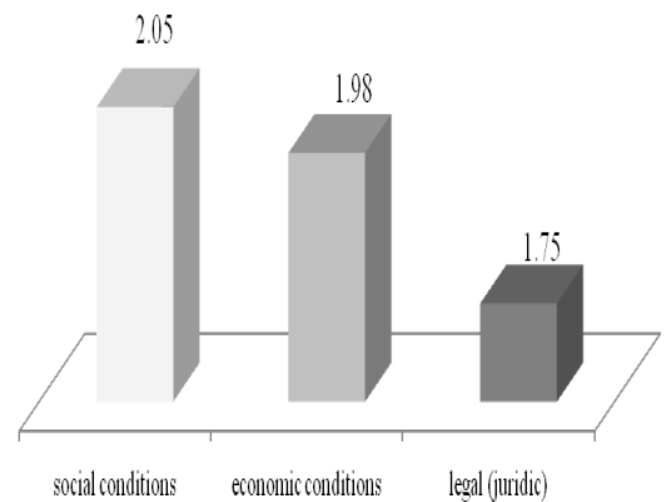

Fig. 1. Assessment of conditions for the development of social entrepreneurship in the Republic (on a five-point rating scale)

The additional analysis of the two-dimensional distribution of the data showed that the increase in points for all parameters is observed as the level of income and education of the respondents increases, and there is the decrease in points when the age of the participants in the expert survey increases.

When disclosing the indicator "the level of development of social entrepreneurship", it is noted that the higher the assessment of this level, the more favorable are the conditions for its formation and further development in this territory.

According to the data obtained, every other survey participant considers the level of development of social entrepreneurship to be low (53.1\%). The number of those who chose the "high" option is three times less than the number of those who chose the "medium" option (7.1 to $24.4 \%$ ). $15.4 \%$ of the respondents found difficulty in replying (Fig. 2).

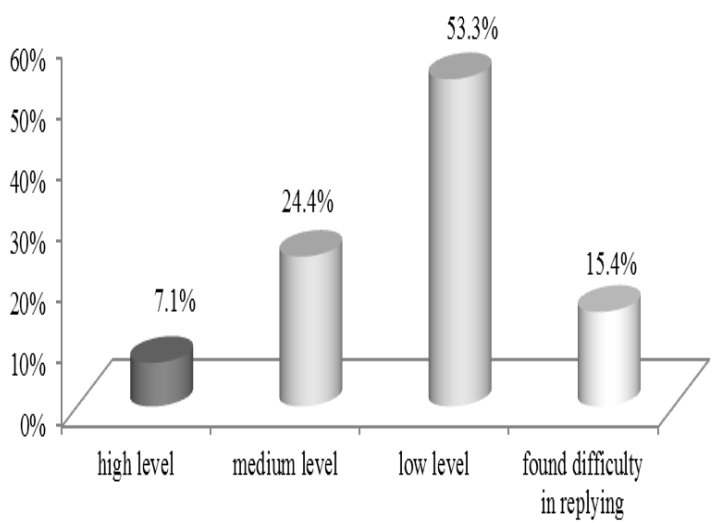

Fig. 2. Assessment of the level of development of social entrepreneurship in the Republic
During the survey, the respondents were asked to evaluate how comfortable are the conditions for the development of social entrepreneurship in the Republic of Tatarstan. The conditions were divided into three subgroups: social, economic and legal (juridic). The assessment was carried out analyzed the conditions for the the development of social entrepreneurship in the Republic of Tatarstan in 2019. Representatives of small and medium-sized businesses ( 8 respondents), organizers of volunteer movement (6 respondents) and directors of charitable organizations (2 respondents) acted as the experts.

\section{RESULTS}

[Milewski P. Feel Good and Do Well by Doing Good: A Proposition That Social Entrepreneurship and Corporate Social Responsibility Can Be the Model for Business Success and Personal Happiness. Cordwood Path, LLC.].

Using an expert survey as a research method, this study responsibility with the executive directors of East Bank (Bob (Sushil Tuli) and Cape Cod Five Cents Savings Bank (David Brennan and Dorothy Savarese). The basic idea is that social

(n)


The overall picture of the development of social entrepreneurship was supplemented by the question of what problems concern the population at present. The most relevant issues were such aspects as raising tariffs for housing and communal services and low income (49 and 33.8\%). A quarter of the respondents pointed out the problems in healthcare, as well as bribery, bureaucratic red tape, rudeness and inattention on the part of officials (28.7 and 26.5\%). According to the experts, every fifth citizen of the Republic is worried about the deterioration of the environmental situation, staff reduction and closure of enterprises (18 and 17.2\%).

About $14.3 \%$ of the respondents noted the spread of drug addiction and alcoholism in our society. Every tenth resident cares about high taxes, poor road conditions, lack of money for the most necessary things and the problem of unemployment $(11,11,10.8$ and $9.7 \%$, respectively). Street crime, police arbitrariness, homelessness or lack of living space, non-payment or delay of wages are less pressing problems in everyday life $(6.7 ; 5.8 ; 4.3$ and $2.7 \%$, respectively) (Fig. 3).

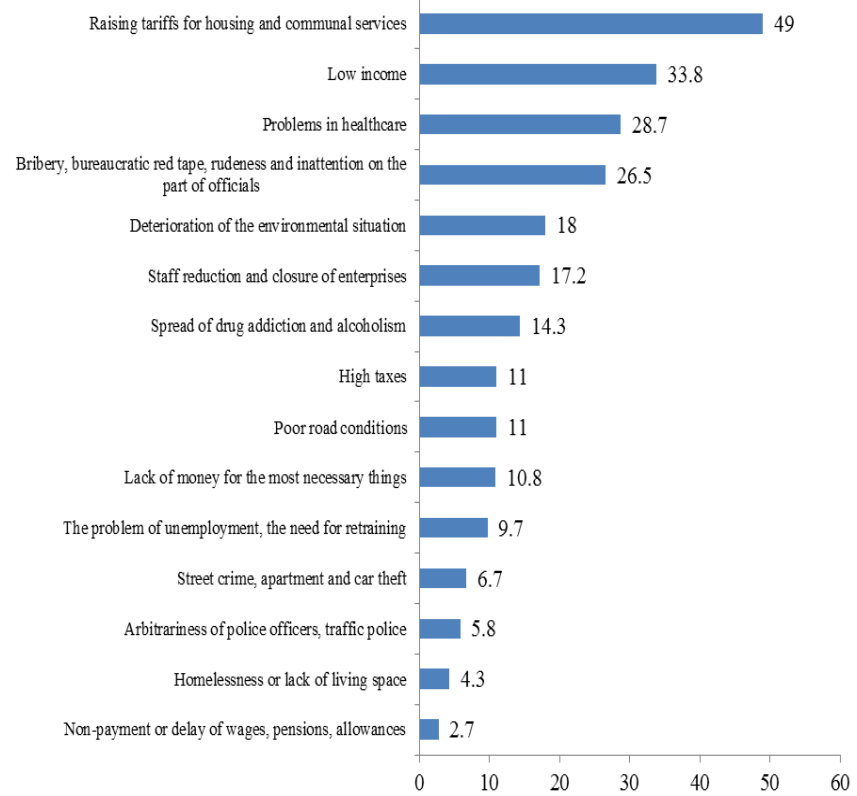

Fig. 3. The most pressing problems at present

A block of questions was devoted to the difficulties of entrepreneurship in general. According to $34.3 \%$ of the respondents, "lack of initial capital" hinders "starting their own business". The instability of the economic situation in the country as an obstacle is indicated by $19 \%$ of the experts. Difficulty in opening one's own business in the form of administrative delays, a complex taxation system and an imperfect legal framework are an obstacle to "starting your own business" in every tenth case (12.2 and 10.8\%). Competition and corruption, bribery of officials as interference are considered by 8.7 and $8.5 \%$ of respondents. High interest on loans from banks would stop $12.5 \%$ of the respondents. Laziness and lack of initiative were noted by $4.2 \%$ of experts. $5.5 \%$ referred to obstacles such as lack of assistance from the State, and $6.2 \%$ of survey participants made reference to high rents and expensive utilities. Least of all, according to the respondents, the population fears crime and bandits (2.5\%) (Fig. 4).

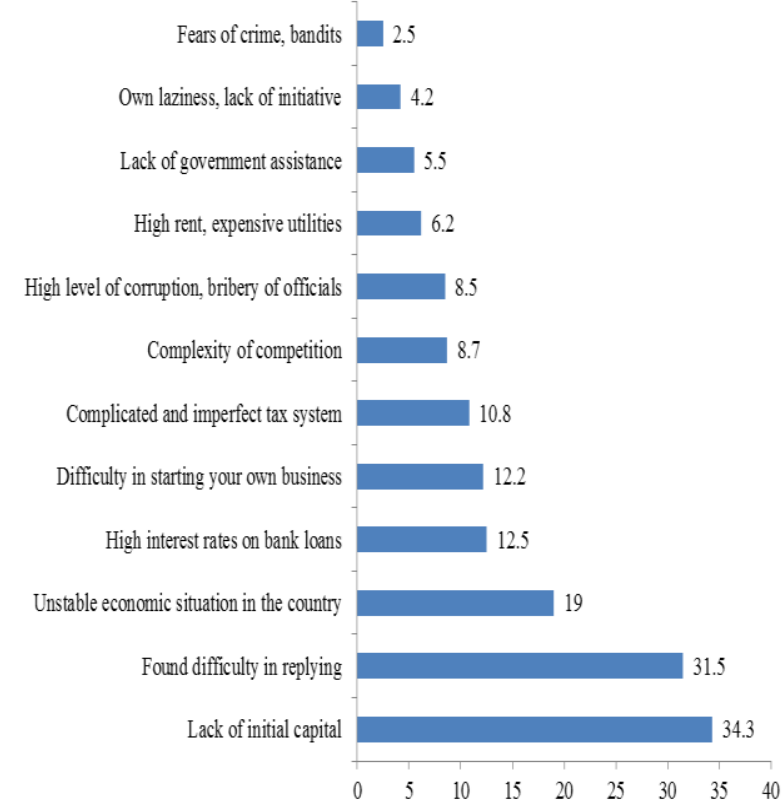

Fig. 4. Obstacles for starting a business

\section{DISCUSSION}

The main guideline of social entrepreneurship is the focus on solving social problems that are relevant and largely "topical" in nature. Their solution should be aimed at improving life of the society and its citizens. In accordance with this, the semi-formalized interview questionnaire contained an open question: "What directions can you offer for social entrepreneurship in the Republic of Tatarstan?". When answering it, the experts proposed the following areas that can and should be developed in the Republic:

- the organization of social fitness centers, visits to which will be accessible to low-income and socially unprotected citizens, the organization of training and education in courtyards, free workshops, the popularization of wellness and general strengthening procedures, gymnastics, etc. Activities for the construction of sports complexes in courtyards, manufacturing sports grounds, hockey rinks, volleyball and basketball playgrounds;

- establishment of a farm on the basis of a family orphanage or a boarding house;

- organization of classes for local clubs, devisions, cultural and creative development studios for youth, parents with disabled children, the poor, etc.;

- services of bathhouses, saunas, hairdressers that will provide their services (for example, once a weekly or monthly) on the basis of charity. 
[11] A.I. Usmanova, "Social responsibility of entrepreneurship in the Republic of Tatarstan", Science Time, vol. 4(16), 2015, pp. 774-775.

Thus, for the development of these areas, according to the experts, the Republic should pay attention to the development of legal (juridic) and economic conditions. Generally, in assessing the development of social entrepreneurship the answer "low level" prevailed, and the lack of initial capital and economic instability in the country were noted as difficulties.

\section{REFERENCES}

[1] V.V. Zhokhov, "Social Entrepreneurship: Essence and Concept: Bulletin of the Far Eastern Federal University", Economics and Management, vol. 1(75), 2015, pp. 85-98.

[2] A. Makarevich, T. Sazonova, "The essence and specificity of social entrepreneurship in Russia", Russian Entrepreneurship, vol. 24(222), 2012, pp. 52-56.

[3] E.S. Yushko, "The essence of social entrepreneurship in modern conditions", Young scientist, vol. 16, 2014, pp. 297-299.

[4] E.E. Khoreva, "Social entrepreneurship: essence, problems, prospects", Synergy of Sciences, vol. 7, 2017, p. 26-31.

[5] N.S. Volkova, "The concept and essence of social entrepreneurship", Economics and society, vol. 7(26), 2016, pp. 468-471.

[6] O.D. Starikova, I.A. Dagaeva, "Social entrepreneurship: the essence and ways of becoming: Innovative processes in the economy, management and social communications", Collection of materials of an international scientific conference, 2015, pp. 247-256.

[7] A.V. Mukhin "The evolution of the concept of social entrepreneurship. main functions of social entrepreneurship", New technologies, vol. 2, 2011, p. 103-106.

[8] N.Z. Sayfudinova, A.V. Makhiyanova, R.A. Timofeev, "Methodological basis of the regional systems socio-economic profile using survey method", Journal of Economics and Economic Education Research, vol. 17(2), 2016.

[9] D.A. Kalugina, G.G. Klimova, "State support of entrepreneurship and social entrepreneurship as a way to overcome the problem of social inequality", Questions of political science and sociology, vol. 2(5), 2013, pp. 27-36.

[10] V.V. Ivanova, "Basic accessibility of state support for entrepreneurship in Russia", Sustainable Development Management, vol. 1(14), 2018, pp. 48-50.
[12] A.K. Kochneva, A.N. Tikhonova, O.N. Ustyuzhina, "Social entrepreneurship in the Republic of Tatarstan: realities and development prospects", NovaUm.Ru, vol. 16, 2018, pp. 205-208.

[13] S.A. Bashkirceva, "Model of Business Economics at the meso level (on the Republic Tatarstan example)"', Bulletin of the Belgorod University of Cooperation, Economics and Law, vol. 4(71), 2018, pp. 298-307.

[14] V.A. Kuznetsova, E.F. Khuzieva, "Social entrepreneurship in the Republic of Tatarstan: Research, systematization, cooperation, development, analysis of socio-economic systems in the field of economics and management (ISKRA - 2018)", Proceedings of the I AllRussian School of Young Scientists, 2018, p. 37-42.

[15] A.V. Makhiyanova, T.A. Burganova, E.F. Huzieva, "Trends to the social structure formation of rural society: the ideal and real models", The 4th International Congress on Interdisciplinary Behavior and Social Science, 2015, p. 49-54.

[16] V.V. Shlychkov, I.K. Kiyamov, S.M. Kulish, D.R. Nestulaeva, I.G. Alafuzov, "Modern Practice of 'Manual Management' in Russian Governmental and Municipal Authority", Journal of Advanced Research in Law and Economics, vol. 8(7), 2018, pp. 2241-2252.

[17] A.I. Grishin, M.S. Melnikov, I.A. Stroganov, "Social entrepreneurship and social business projects within the framework of the concept of sustainable development", Academy Herald, vol. 1, 2015, pp. 9-15.

[18] A.V. Makhiyanova, D.M. Shakirova, A.A. Mavlyudov, I.I. Chechetkina, L.V. Rakhmatullina, "Social Portrait of Project Organizations: Methodological Aspects of Conflict Relations Diagnostics", Jour of Adv Research in Dynamical \& Control Systems, vol. 11(3), 2019, p. 879883.

[19] I.S. Pakulina, "Social entrepreneurship as a tool for solving the socioeconomic problems of the region", Bulletin of the Tula State University. Economic and legal sciences, vol. 2-1, 2011, p. 289-298.

[20] M.R. Zainullina, A.V. Makhiyanova, E. F. Khuzieva, R.M. Nagimov, "Methodology of construction and trend shaping for economic profile of poverty", International Transaction Journal of Engineering, Management, \& Applied Sciences \& Technologies, vol. 10(1), 2019, p.27-35.

[21] P. Milewski, Feel Good and Do Well by Doing Good: A Proposition That Social Entrepreneurship and Corporate Social Responsibility Can Be the Model for Business Success and Personal Happiness, 2019, pp.112-113. 